\title{
Design for an "engineered sinkhole" to improve, recharge and reduce evapotranspiration in an upstream flood control structure
}

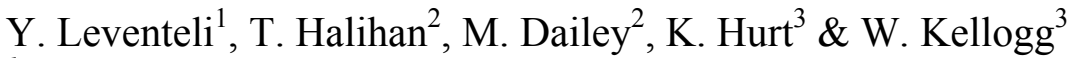 \\ ${ }^{I}$ Faculty of Engineering, Akdeniz University, Turkey \\ ${ }^{2}$ School of Geology, Oklahoma State University, USA \\ ${ }^{3}$ Chickasaw Nation, USA
}

\begin{abstract}
Freshwater resource shortages have become a significant problem in the world due to population growth, rural to urban migration, climate change, and flood control. When water is stored above ground, mass amounts of water are lost due to evapotranspiration. In order to curb the freshwater resource shortage we propose the following solutions: 1) preventing some storm water from becoming runoff, 2) keeping water clean, 3) storing water underground, and 4) using water more intelligently.

Flood control structures, thousands in the United States alone, have been utilized around the world to reduce peak flow to streams in order to avoid property damage. However, these structures store the excess water with little benefit, reduce recharge, and increase evapotranspiration.

Artificial recharge is the process of augmenting groundwater through the intervention of man's activities- either intentional or unintentional. The goal in artificially recharging water to an aquifer is to increase the long term stability of a clean water supply to both people and the environment. Water stored in aquifers is not subjected to the evaporative losses of surface storage areas (e.g. lakes and ponds). One of the advantages of storing water in aquifers is that the risks associated with anthropogenic or natural contamination are reduced and environmental and surface impacts are mitigated.

This research presents a design to integrate flood control measures with artificial recharge structures in order to provide better flood control and improve
\end{abstract}


recharge without sacrificing water quality. This study evaluated alternatives for artificial recharge in terms of environment, safety, and economy for upstream flood control dam \#37 in southern Oklahoma. An "engineered sinkhole" is proposed that will maintain flood control while allowing artificial recharge to proceed without sacrificing water quality.

Keywords: artificial recharge, engineered sinkhole, Oklahoma, upstream flood control structure, Arbuckle-Simpson aquifer.

\section{Introduction}

In order to increase the supply of groundwater, artificial recharge has been employed using many different techniques in many different areas around the world. Artificial recharge may be defined as "augmenting the natural movement of surface water into underground formations by some methods of construction, by spreading of water, or by artificially changing natural conditions" [1]. The factors governing the choice of site specific artificial recharge methods include climate, hydrogeology, topography, source water availability and quality, operational and management issues, regulatory controls and environmental and socio-economic considerations with topography, climate, and hydrogeology being the major concerns.

The Wingard Ranch study area, in south-central Oklahoma between the small communities of Fitzhugh and Roff, is used primarily for cattle grazing. The Blue River, which is ephemeral along this reach, runs through the property (Figure 1).

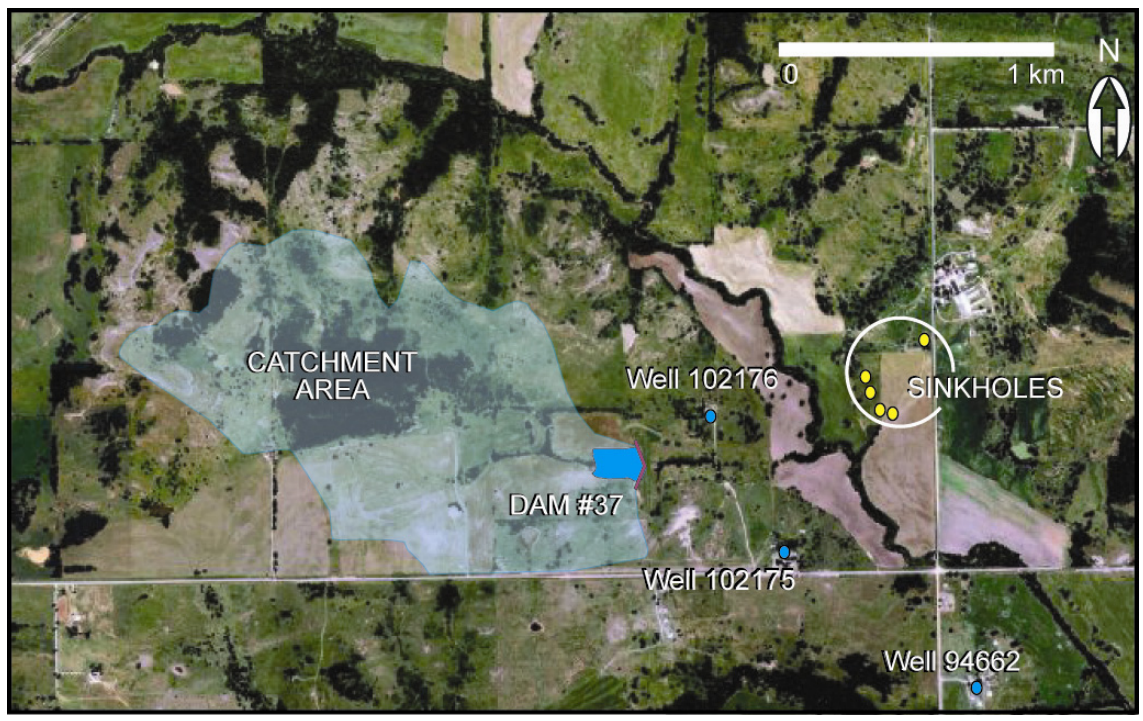

Figure 1. Aerial photograph of the study site with the location of dam \#37 and its catchment area illustrated. Riparian zones darker due to high tree density [aerial photograph from 5]. 
Numerous sinkholes are located on the east side of the Blue River. These sinkholes serve as natural recharge features for the aquifer. Upstream Flood Control Dam \#37 was built as a watershed dam in 2000 on the Wingard Ranch and occupies 1.6 hectares at the conservation pool and has a flood storage capacity of approximately $185,000 \mathrm{~m}^{3}$ [2]. The watershed drains approximately 180 hectares [2]. With an average rainfall of $1.01 \mathrm{~m} \mathrm{[3]} \mathrm{and} \mathrm{assuming} \mathrm{a} \mathrm{runoff}$ coefficient of 0.2 , this watershed is capable of generating $287,000 \mathrm{~m}^{3}$ of runoff. Overflow from the dam is discharged through an outlet structure into a plunge pool where the water eventually drains into the Blue River located approximately $650 \mathrm{~m}$ to the east.

While this structure and pool is constructed on a sandstone formation that has shale interbeds that limit vertical permeability, the nearby sinkholes allow rapid recharge into the underlying carbonate formation. In this study, an "engineered sinkhole" design is evaluated as an artificial recharge method in terms of environment safety, and economy for the Wingard Ranch and its upstream flood control structure.

\section{Climate and topography}

The average temperature is $16.7^{\circ}$ Celsius. The average annual precipitation is $1.01 \mathrm{~m} \mathrm{[3]}$. The majority of precipitation happens during the spring months followed by dry summers. The annual lake evaporation averages $1.4 \mathrm{~m}$ with $70 \%$ occurring from May to October [4].

The elevation ranges between $335 \mathrm{~m}$ and $396 \mathrm{~m}$ in the study area, fig. 1 . The northeastern portion of the study area has relatively rough topography while the area around the watershed dam has a relatively flat landscape (less than $3 \%$ slope). The Blue River and its tributaries trend northwest to southeast. The elevation of Blue River is $354 \mathrm{~m}$ in the northwest and $344 \mathrm{~m}$ in the southeast in the study area. The tributary of the Blue River, which the dam is located on, starts from $372 \mathrm{~m}$ and combines with the main stream at $349 \mathrm{~m}$. The dam's overflow elevation is $354 \mathrm{~m} \mathrm{[2].}$

\section{Hydrogeology}

The geological and structural setting has an important influence on site selection for artificial recharge. The overlying formations, with their thickness and aerial extent, affect the input to aquifers and the methods used to recharge the aquifer. The spatial extents of the formations are shown in figure 2.

According to Fairchild et al. [6], the study site is located over the ArbuckleSimpson aquifer. There are two main groups in the study area, the Arbuckle and the Simpson Group. The Simpson Group in the area consists mainly of a gray to tan limestone with a greenish-gray shale and fine to medium grained, brown sandstone with its depth ranging between $1 \mathrm{~m}$ and $76 \mathrm{~m}$. The Arbuckle Group in the area is mainly a gray to tan limestone, which grades eastward into a tan dolomite with some stringers of shale and sandstone, with a thickness of more than $300 \mathrm{~m}$. There is a fault on the north side of the Simpson Group in the study area. 


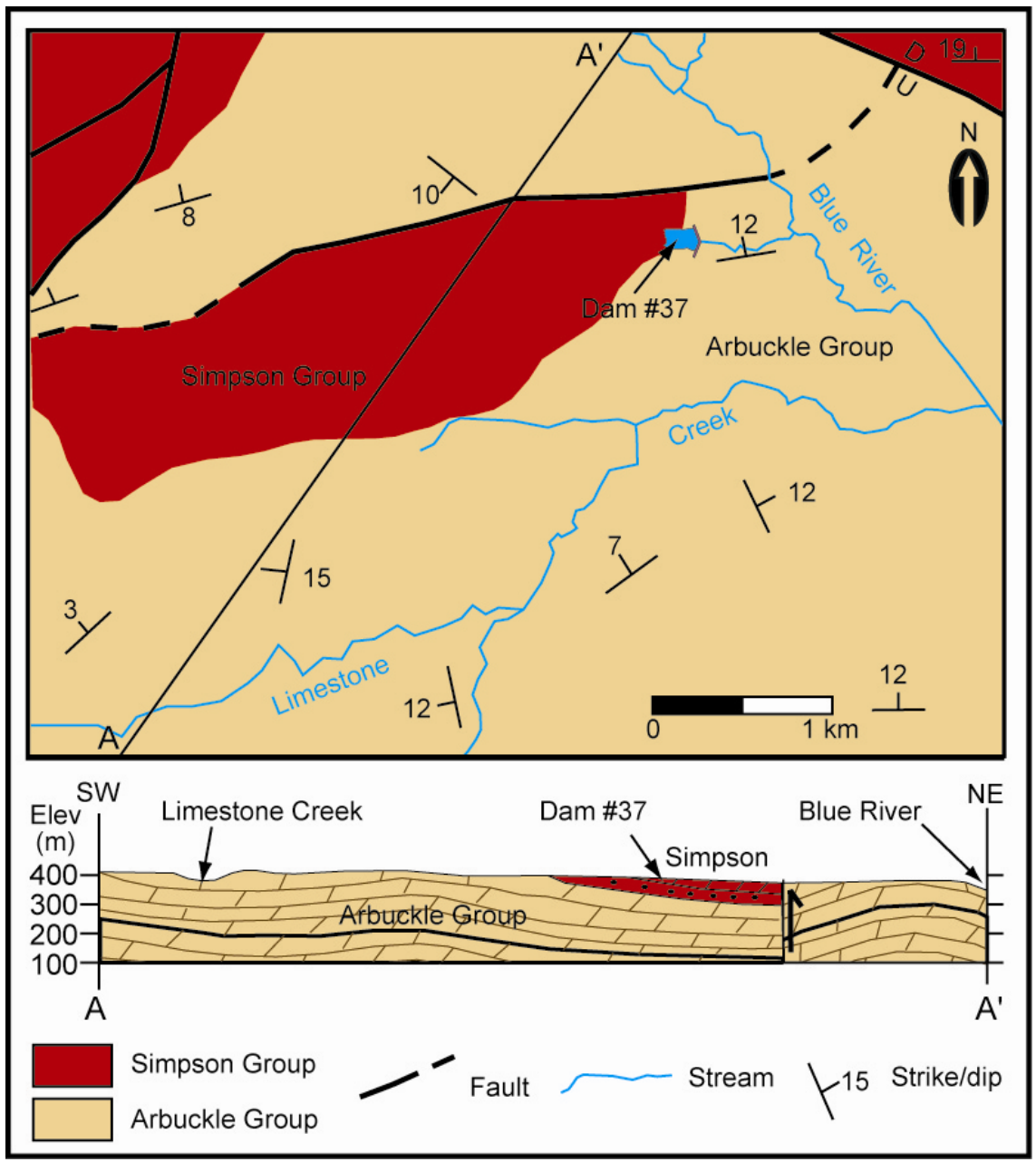

Figure 2. Geological map of the study area [adapted from 6].

This unit is thick in the north (adjacent to the fault) and thins to the south. The thickness of the Simpson Group changes from $1 \mathrm{~m}$ to $76 \mathrm{~m}$ in the study area [6].

Bogard [4] has identified three types of soils in the study area: the Port and Cleora soils (Pr), the Fitzhugh fine sandy loam (FhC2), and the Durant and Bates soils (DvC3). These low permeable soils are referred to as "vegetative soils" [4]. The thickness of the vegetative soil varies between $2 \mathrm{~cm}$ and $3.7 \mathrm{~m}$.

The Arbuckle-Simpson aquifer is generally an unconfined carbonate aquifer (Arbuckle Group) with a sandstone (Simpson Group) overlying the Arbuckle Group in some locations. This fractured aquifer has good storage capacity in the soil zone and in the fractures in the aquifer and high transmissivity.

Due to heavy faulting in the study area, the occurrence and movement of groundwater in the Arbuckle-Simpson are strongly controlled by geologic 
structure. The association of springs with faults and other fractures indicates the significance of structural control on groundwater flow. The streams, like the Blue River and its tributaries, are fed by springs that issue from the aquifer [6].

The potentiometric level ranges from $335 \mathrm{~m}$ to $358 \mathrm{~m}$ [6] in the study area. The wells in the area show that groundwater is relatively shallow with estimated depths ranging from 14 to 43 meters.

\section{Proposed artificial recharge system}

Decision making protocols are already in place for the design of artificial recharge structures [7], but they are influenced by the presence of the existing upstream flood control dam. The reservoir can act as a settling basin and allows photodegradation of runoff water. With the dam in place, an "engineered sinkhole" is proposed to allow recharge, while filtering and providing a system that will require as little long term maintenance as possible, fig. 3.

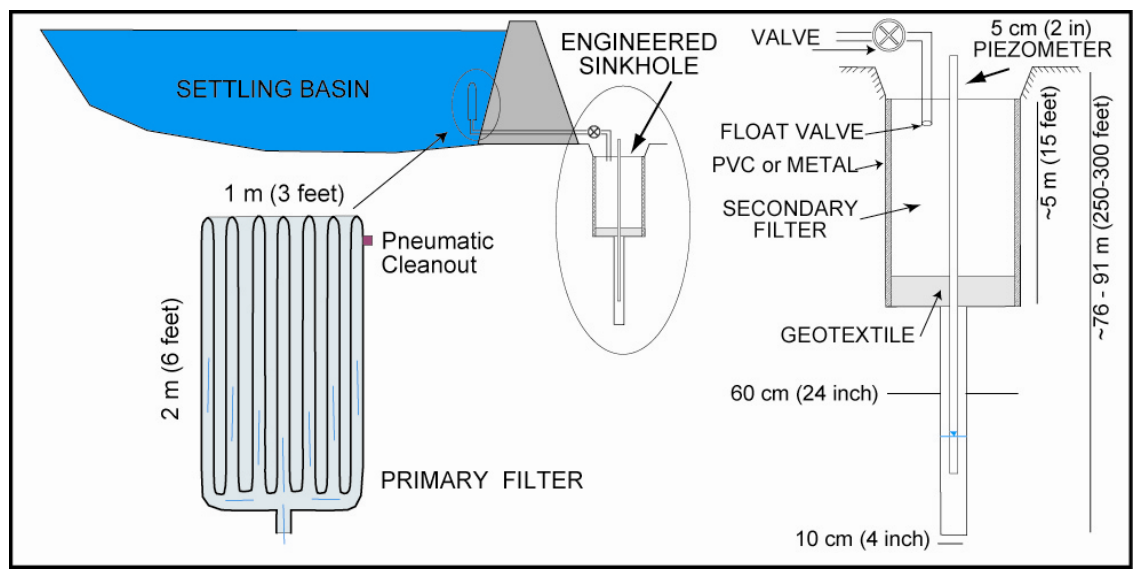

Figure 3. Schematic of the proposed artificial recharge system for Wingard Ranch.

The dam already in place to store fresh water from high precipitation events is the first component of the artificial recharge system. Besides this earth embankment dam, the recharge system has two additional components- the primary filter and the engineered sinkhole.

The primary filter is located in the basin next to the dam to filter fine sediments before the stored water will be diverted to the engineering sinkhole by a pipeline. The size of this filter is 1 meter by 2 meters. The main advantages of the primary filter are that the filter will remove sediment from the storm water when the dam is full and the filter will be cleaned by wind removing built up sediment when the dam is empty limiting maintenance. A pneumatic cleanout is also part of the design for maintenance if the filter does clog. The infiltrated water will then be transmitted via pipe to the engineered sinkhole. This pipe has 
a $10 \mathrm{~cm}$ diameter, a shut off valve, and a float valve to control the flow of the storm water.

The engineered sinkhole is composed of two parts- the secondary filter (upper) and the well (lower). The size of the filtration system is $60 \mathrm{~cm}$ diameter $\times 5 \mathrm{~m}$ long. The filtration system includes PVC or metal casing on the walls to block leakage, sand as a secondary filtration, and a layer of geotextiles at the bottom to prevent the sand filter from migrating into the well. The recharge well will be 20.3 $\mathrm{cm}$ (4 in) in diameter and approximately 76-91 m (250-300 ft) deep. A piezometer will be used to monitor groundwater levels and recharge water quality.

Although the proposed recharge well requires drilling and special design it is advantageous as the climate is sub-arid and land is costly. A recharge well will deliver surface waters directly into the deep aquifer and therefore bypass the low permeable soils and the rocks of the Simpson group. The main disadvantage that may exist is clogging by fines or biofouling. However, the infiltration system design helps to prolong the life by using the wetting and drying phases to limit these problems.

\section{Discussion}

Thousands of upstream flood control structures exist in the United States with 2101 in Oklahoma alone. These make excellent sites for recharge structures for several reasons: the water gathering structure that would be required for recharge is already constructed, the structure provides a pre-existing settling pond to reduce suspended solids from entering an aquifer, they would be expected to dry out and may not be allocated to significant surface uses, and since they dry out, they would limit the amount of growth of algae or other clogging substances allowing the structure to regenerate itself.

There are many options for recharge structures, however based on geologic and climate restraints, the majority of them are not a sound choice for the Wingard Ranch. The sub-arid climate, flat topography, high evapotranspiration, high clogging rates from microbial growth, potential impacts from cattle production, and low permeable soil covering are not ideal for spreading methods. This leaves the deeper methods such as wells.

As biological clogging will likely be the strongest maintenance issue for the recharge well, a modified design is provided. The design takes into account the benefits of using an upstream flood control structure. The primary benefit is the structure currently provided a settling basin, and is unlikely to flow continuously. Using this intermittent flow, the clogging issues can be minimized through careful design.

Cost is always an important aspect of choosing a system. The costs for evaluating, installing, operating, and maintaining a recharge structure on an upstream flood control structure include study costs, drilling costs for installing the system, filters and equipment to outfit the system, a weather station, sampling to monitor the system, and labor costs for permitting.

If the source water is suitable, a well will need to be drilled and tested to determine the intake rate of the formation at the site of the engineered sinkhole 
as the aquifer variability is significant in this type of formation. With the float valve in the system, the transmissivity can be quite low as the dam can remain full for several months while the water infiltrates the system. At this site the transmissivity is high enough to make the drainage time less than a week and perhaps less than one day for most rain events. The dam will also need to have a horizontal boring installed to allow the system to be installed. The total drilling costs are estimated at $\$ 66,000$. The filter systems and valves to be installed are estimated at $\$ 3,000$. An onsite weather station is estimated at $\$ 48,300$. The remaining testing, construction, and permitting costs are estimated to be $\$ 22,000$. Operation and maintenance costs for the structure include analysis of water samples and permitting, maintaining the weather station and transducers, and inspection and cleaning of the filter structures, if required. These costs are estimated at $\$ 23,000$ per year, but may be reduced if the design works well and sampling and maintenance can be decreased after several years of operation.

There are two primary changes to the basin water budget that will be imposed on upstream flood control structure \#37 if it is outfitted with an engineered sinkhole. First, runoff would be reduced to zero except in potentially extreme floods where the overflow to the dam would cause water to leave the system. Secondly, the evaporation and transpiration of the system would be reduced substantially. Impacts to the Blue River's environment should be minimal as the stream is ephemeral along this reach. A decreased amount of surface water input is unlikely to have a bearing on the Blue River, especially since only a nominal amount of the water from the conservation pool usually reaches it.

For the $287,000 \mathrm{~m}^{3}$ of runoff entering the system, the distribution of the runoff was estimated as $5.6 \%\left(16,000 \mathrm{~m}^{3}\right)$ to direct evaporation, with an equivalent amount of transpiration near the lake. Natural groundwater recharge is assumed to be negligible, leaving the remaining $88.8 \%\left(255,000 \mathrm{~m}^{3}\right)$ of the budget as surface runoff out of the system. With the addition of the recharge system, this should reduce evaporation by approximately $90 \%$ to $1600 \mathrm{~m}^{3}$ per year of the runoff budget. It is assumed that the recharge structure will do little to limit transpiration, so the budget for transpiration will remain unchanged for the runoff budget. If surface water outflow is converted to groundwater recharge, it will result in a recharge of $269,000 \mathrm{~m}^{3}$ from the system. If water is traded in the basin, the system will act as a net gain to the water budget for the basin, and can potentially be used as a new resource in the basin for trading purposes.

\section{Conclusions}

Evaluation of the Wingard Ranch upstream flood control dam \#37 indicates that the site will provide a suitable location for a recharge structure. The design of the "engineered sinkhole" structure is meant to simulate a sinkhole with better control on the filtering of the recharge water than exists for natural sinkholes in the area.

The site has constraints of high water quality in the aquifer. If the source water has lower quality, a recharge structure may not be possible, but the 
proposed settling and filtering mechanisms of the recharge design may solve any possible source water issues. As surface water already enters the aquifer through sinkholes, this is not expected to be a problem.

The residence time of recharge water is a second issue that needs to be addressed. If the residence time is too low, not only will the aquifer not be able to improve the water quality through common mechanisms, but the water won't be around long enough to make any significant differences in the basin as it will be discharged to the surface too quickly. The close proximity of Byrd's Mill Spring, which is used for municipal water supply, makes this evaluation more complex and a tracer test will be needed before the structure can be put online.

The water budgeting for the site indicates that approximately $269,000 \mathrm{~m}^{3}$ of water could be recharged by the site, with $14,800 \mathrm{~m}^{3}$ of water that would be lost to evaporation if no changes were made to the upstream flood control structure.

\section{Acknowledgements}

The authors wish to thank the late Harold Wingard for his support with this project. We are indebted to him for his help, cooperation and kindness. The authors also wish to thank the Scientific Research Projects Unit at Akdeniz University and the Bureau of Reclamation for financial support. Finally, we wish to thank Collins Balcombe and W. Robert Talbot for their invaluable assistance.

\section{References}

[1] Todd, D.K., \& Mays, L.W., Groundwater Hydrology, John Wiley \& Sons, Inc., New York, p. 251, 1959.

[2] Natural Resources Conservation Service, Upper Blue River watershed floodwater retarding structure site no. 37, Engineering Design Drawings, Stillwater, OK, 17 pp, 1999.

[3] Oklahoma Climatological Survey, http://climate.mesonet.org.

[4] Bogard, V.A., Soil Survey of Pontotoc County, Oklahoma, United States Department of Agriculture Soil Conservation Service: Washington D.C., 1973, pp. 1-34, 1973.

[5] Terraserver, http://www.terraserver.com.

[6] Fairchild, R.W., Hanson, R.L., \& Davis, R.E., Hydrology of the Arbuckle Mountains Area, South-Central Oklahoma, Circular 91, Oklahoma Geologic Survey, Norman, OK, 112 pp. \& 2 plates, 1990.

[7] Gale, I.N., Neumann, I., Calow, R.C., \& Moench, M., The Effectiveness of Artificial Recharge of Groundwater: a Review, British Geologic Survey Commission Report, Keyworth, Nottingham, 59 pp., 2002. 